\title{
Phosphorylation of vasodilator stimulated phosphoprotein is correlated with cell cycle progression in HeLa cells
}

\author{
YAN TAO, YONG-CHANG CHEN, JIAN-RONG SANG and WEN-RONG XU \\ School of Medical Science and Laboratory Medicine, Jiangsu University, Jiangsu 212013, P.R. China
}

Received March 24, 2010; Accepted May 31, 2010

DOI: $10.3892 / \mathrm{mmr} 00000312$

\begin{abstract}
Vasodilator stimulated phosphoprotein (VASP) is known as an actin-binding protein. The phosphorylation of VASP plays an important role in its function. In a previous study, serine 157 phosphorylated VASP (p-VASP S157) was shown to be co-localized with $\alpha$-tubulin on the spindle of SGC-7901 cells. In the present study, we demonstrated that the level of p-VASP S157 increases and has a peak which coincides with serine 10 phosphorylated histone 3 (p-H3 S10) during mitotic progression in a human cervical cancer cell line (HeLa cells). Application of protein kinase A inhibitor H89, protein kinase G inhibitor KT5823 and protein kinase C inhibitor G06983, or a combination of these inhibitors, caused a partial decrease in p-VASP S157 and a delay in $\mathrm{G}_{2} / \mathrm{M}$ progression. Depletion of p-VASP S157 by VASP siRNA resulted in an increase in binucleated cells and $x 4 n$ cells, a further delay in $\mathrm{G}_{2} / \mathrm{M}$ progression and the inhibition of HeLa cell proliferation. These results suggest that p-VASP S157 may play an important role in the $\mathrm{G}_{2} / \mathrm{M}$ transition and the completion of cytokinesis in HeLa cells.
\end{abstract}

\section{Introduction}

The cell cycle, which underlies all biological growth and reproduction processes, is the sequence of events that produces two nearly identical cells from one original. In eukaryotic cells, DNA replication and sister chromatin separation are temporally divided into distinct phases of the cell cycle: the $\mathrm{S}$ phase (for DNA synthesis) and the M phase (for mitosis). Certain cellular structures are crucial to the cell cycle process, and the mitotic spindle is one of these. This cellular structure plays a role in the cell cycle by mediating chromosome segregation during mitosis. Errors in spindle formation result in both chromosome missegregation and cytokinesis defects, which lead

Correspondence to: Dr Yong-Chang Chen, School of Medical Science and Laboratory Medicine, Jiangsu University, \#301 Xue Road, Zhenjiang, Jiangsu 212013, P.R. China

E-mail: ycchen54@ujs.edu.cn

Key words: vasodilator stimulated phosphoprotein (VASP), phosphorylated VASP, cell cycle, $\mathrm{G}_{2} / \mathrm{M}$, cytokinesis to genomic instability (1). The mitotic spindle is a complex microtubule (MT)-based cellular structure based on a bipolar array of MTs and interacting proteins. The formation of the spindle involves dramatic changes in MTs and the recruitment of specific spindle-associated proteins that facilitate function in the mitotic phase (2-7). Certain proteins with important functions in the assembly of the mitotic spindle are those also crucial to the cell cycle, such as tastin and interphase nucleus and mitotic apparatus-associated protein (INMAP) $(8,9)$.

Proteins of the Ena/VASP family are a group of multifunctional proteins associated with the regulation of actin $(10,11)$. In mammals, the Ena/VASP family consists of three proteins, including mammalian Ena, VASP and Ena-VASP-like protein. VASP is known to be a substrate for PKA, PKG and PKC in a variety of cells (12-14) and participates in actin-fiber formation. Its activity is regulated by phosphorylation. VASP harbors three phosphorylation sites: S157, located N-terminally to the central proline-rich region, and S239 and T278, located in the Ena/VASP-homology domain 2 (15-17). The phosphorylation of VASP plays an important role in its function. However, the precise functional mechanism of the specific phosphorylation remains unknown.

In a previous study, we demonstrated for the first time that p-VASP S157, not VASP, was co-localized with $\alpha$-tubulin on the spindles of the gastric cancer cell line SGC-7901, suggesting that p-VASP S157 may have an important role in the assembly of this cellular structure (18). Considering that spindle-associated proteins, such as tastin and INMAP, play a crucial role in the cell cycle, we performed the following experiments to identify p-VASP as a new regulator of $\mathrm{G}_{2} / \mathrm{M}$ progression in HeLa cells.

\section{Materials and methods}

Cell lines. The human cervical cancer cell line HeLa was provided by the Institute of Cell Biology (Shanghai, P.R. China).

Reagents. Dulbecco's modified Eagle's medium (DMEM) was purchased from Gibco (Grand Island, NY, USA). New-born calf serum (NBCS) was from Minhai Bio-engineering Co. (Lanzhou, P.R. China). Antibodies against VASP (cat. no. sc-46668) and phosphorylated VASP (cat. nos. sc-23506-R and sc-23507) were from Santa Cruz Biotechnology (Santa Cruz, CA, USA). Antibody against $\alpha$-tubulin (BM1452) was from Foster Biological Technology Ltd. (Wuhan, P.R. China). 
A



B





C



D

$\begin{array}{llllll}0 & 4 & 6 & 8 & 10 & 14 \mathrm{~h} \text { post thy block }\end{array}$



Figure 1. p-VASP S157, but not S239, increases during the $\mathrm{G}_{2} / \mathrm{M}$ transition. (A and B) Results of immunofluorescence microscopy. (A) HeLa cells were stained with antibodies against- $\alpha$-tubulin (green) and p-VASP S239 (red), and with nuclear Hoechst 33342 dye (blue). (B) HeLa cells were visualized with antibodies against actin (green), p-VASP S239 (red) and Hoechst 33342 (blue). (C and D) Results of Western blotting. HeLa cells were synchronized with a double thymidine block and released into fresh medium, whole cell extracts were prepared at different time points after release from the block and were analyzed by Western blotting with antibodies against (C) VASP, p-H3 S10, GAPDH and p-VASP S157, and with antibodies against (D) VASP, p-H3 S10, GAPDH and p-VASP S239. GAPDH expression served as the control.

FITC, TRITC and peroxidase-conjugated secondary antibodies were from Jackson ImmunoResearch Laboratories (West Grove, PA, USA). Antibody against glyceraldehyde phosphate dehydrogenase (GAPDH) was from Kangcheng (Hangzhou, P.R. China). Antibody against Phospho-Histone H3 S10 (cat. no. 1173-1) was from Epitomics (Burlingame, CA, USA). VASP small interfering RNA (siRNA) (cat. no. sc-29516) and transfection reagent (cat. no. sc-29528) were from Santa Cruz Biotechnology (Santa Cruz, CA, USA). Nuclear fluorochrome Hoechst 33342 was from Sigma (St. Louis, MO, USA). Electrochemiluminescence (ECL) reagents were from Amersham Biosciences (Buckinghamshire, UK).

Cell culture and transfection. HeLa cells were maintained in DMEM supplemented with $10 \%$ FBS (100 IU/ml) and penicillin/streptomycin $(100 \mathrm{mg} / \mathrm{ml})$ and incubated at $37^{\circ} \mathrm{C}$ in $5 \% \mathrm{CO}_{2}$. The cells were seeded in 6-well plates at a density of $20-30 \%$ of confluence and were transfected the following day. Transfection of siRNA was performed according to the manufacturer's instructions.

Fluorescence-activated cell sorter (FACS) analysis. Cells were transfected with siRNA and harvested after $72 \mathrm{~h}$ with trypsin digestion, washed twice in PBS and fixed with cold $70 \%$ ethanol for $30 \mathrm{~min}$ at $4^{\circ} \mathrm{C}$. Cells were washed twice with ice-cold PBS, incubated with $6 \mathrm{mg} / \mathrm{ml}$ propidium iodide and $10 \mathrm{mg} / \mathrm{ml}$ RNAse for $30 \mathrm{~min}$ at room temperature, and analyzed for DNA content by flow cytometry on a FACSCalibur (Becton Dickinson, San Jose, CA, USA).
Preparation of cell extracts. Cells were harvested at various time points by aspiration of the media and the direct addition of 2X SDS sample buffer. The cell lysate was scraped and transferred to tubes, heated for $5 \mathrm{~min}$ at $95^{\circ} \mathrm{C}$ and stored at $-20^{\circ} \mathrm{C}$.

Cell synchronization. For synchronization experiments, cells were seeded in 6-well plates at a density of $20 \%$, transfected as described above and incubated immediately with $2 \mathrm{mM}$ thymidine (Sigma) for $14 \mathrm{~h}$. Cells were then washed three times with PBS and released into fresh medium for $11 \mathrm{~h}$, followed by a second round of incubation with $2 \mathrm{mM}$ thymidine for $15 \mathrm{~h}$. Cells were then washed three times with PBS and fresh medium was added. This time point, corresponding to the $G_{1} / S$ transition, was designated as time 0 . Cells were harvested at the indicated time points and the whole cell extracts were prepared as described above.

Western bloting. Sample proteins were separated on SDS-PAGE gels and blotted onto polyvinyl difluoride (PVDF) membrane. The PVDF membrane was blocked with $3 \%(\mathrm{w} / \mathrm{v})$ bovine serum albumin (BSA) in TBS-T for $1 \mathrm{~h}$ at room temperature. Incubation with the primary antibody was conducted at $4^{\circ} \mathrm{C}$ overnight, and with the secondary antibody for $1 \mathrm{~h}$ at room temperature, with three washes after each incubation. ECL reagents were used to reveal the positive bands on the membrane. The bands were detected by Typhoon 9400 (GE Healthcare, USA).

Immunofluorescence assay. Control and VASP siRNAtransfected cells grown on cover slips were incubated with 



Figure 2. Decrease in p-VASP S157 delays $\mathrm{G}_{2} / \mathrm{M}$ progression. HeLa cells were synchronized with a double thymidine block and released into fresh medium. After $8 \mathrm{~h}$ from releasing, kinase inhibitors were added. The whole cell extracts were prepared after $9 \mathrm{~h}$ from release and analyzed by Western blotting using anti-p-VASP S157, anti-VASP, anti-p-H3 S10 and anti-GAPDH antibodies, respectively. GAPDH served as the control. Cells were treated as follows: A1 and A2, control; B1 and B2, $1 \mu \mathrm{M} \mathrm{H89;}$ C1 and C2, $2 \mu \mathrm{M}$ KT5823; D1 and D2, $1 \mu \mathrm{M}$ Go6983; E1 and E2, combination of the above three inhibitors. The expression of p-H3 S10 and GAPDH proteins in each fraction was detected by Western blotting. Representative band images are shown in the left panels. Densitometric analysis of the bands is shown in the right panels.

$0.2 \mathrm{mmol} / \mathrm{l} \mathrm{Hoechst} 33342$ for $10 \mathrm{~min}$ after $48 \mathrm{~h}$ of transfection to reveal nuclei, and were then fixed with freshly prepared $40 \mathrm{~g} / \mathrm{l}$ paraformaldehyde in PBS at $4^{\circ} \mathrm{C}$ overnight. After being penetrated with $30 \mathrm{ml} / 1$ Triton X-100 and blocked with $30 \mathrm{~g} / \mathrm{l}$ BSA, the cells were incubated with primary antibodies at $4^{\circ} \mathrm{C}$ overnight and then with FITC- or TRITC-conjugated secondary antibodies for $1 \mathrm{~h}$ at room temperature, with three washes after each incubation. The morphologic changes of the cells were analyzed by fluorescence microscopy.

Cellular proliferation assay. HeLa cells were seeded in 96-well plates at a density of $1.2 \times 10^{4} / 100 \mu \mathrm{l}$. After being transfected with VASP siRNA, they were cultured for an additional $72 \mathrm{~h}$. Proliferation of the cells was detected by the 3-(4,5dimethylthiazol-2-yl)-2,5-dimethyl tetrazolium bromide (MTT) colorimetric method (19). The units of absorption were measured using a photometer (Bio-tek MQX200) at a wavelength of $570 \mathrm{~nm}$.

Statistical analysis. Data were expressed as the mean \pm SE. Statistical significance was examined by the Student's t-test. Probability below $0.05(\mathrm{P}<0.05)$ was considered significant.

\section{Results}

p-VASP S157 levels increase during $G_{2} / M$ progression. p-VASP S157 localizes on the spindle of SGC-7901 cells (18). To determine whether p-VASP S157 is the only phosphorylation form related to the spindle, we applied the commercially available antibody against serine 239 phosphorylated VASP (p-VASP S239), another phosphorylation form of VASP, to detect the location of other forms of phosphorylated VASP. p-VASP S239 was found to be colocalized with actin (Fig. 1B), but not $\alpha$-tubulin (Fig. 1A), and did not localize on the spindle. To investigate the phosphorylation of VASP during mitotic progression, cell extracts from synchronized HeLa cells were harvested after release from a double thymidine block and analyzed by Western blot analysis. The results showed that the level of p-VASP S157 increased as the cells were released from thymidine block, and peaked 10-11 $\mathrm{h}$ after release. This process coincided with the observed accumulation of p-H3 S10 (Fig. 1C), a modification which is highly conserved, correlates with chromosome condensation during mitosis and is used as a marker of $\mathrm{G}_{2} / \mathrm{M}$ progression. Again, p-VASP S239 did not increase during the cell cycle (Fig. 1D). These data implied that p-VASP S157, but not p-VASP S239, was involved in $\mathrm{G}_{2} / \mathrm{M}$ progression.

Protein kinase inhibitors decrease the level of $p$-VASP $S 157$ and cause a delay in $G_{2} / M$ progression. Considering that VASP was phosphorylated by PKA, PKG and PKC, we applied H89 (inhibitor of PKA), KT5823 (inhibitor of PKG), and Go6983 (inhibitor of PKC) to inhibit the phosphorylation of VASP and to observe the effects on $\mathrm{G}_{2} / \mathrm{M}$ progression. HeLa cells were synchronized at the $\mathrm{G}_{1} / \mathrm{S}$ boundary with a double thymidine block and were then released into fresh medium. The cells were treated with H89 $(1 \mu \mathrm{M})$, KT5823 $(2 \mu \mathrm{M})$, Go6983 $(1 \mu \mathrm{M})$ or a combination of the inhibitors after $8 \mathrm{~h}$ (after cells had progressed through $\mathrm{S}$ phase) and were harvested after $9 \mathrm{~h}$. The results of Western blotting showed that the treatment caused not only a decrease in p-VASP S157, but also a delay in $\mathrm{p}-\mathrm{H} 3 \mathrm{~S} 10$, which accumulates in prophase 
A



F



B

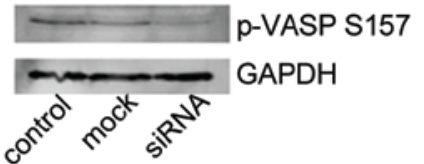

D


E



G



Figure 3. Depletion of VASP and p-VASP S157 causes a further delay in $\mathrm{G}_{2} / \mathrm{M}$ progression and the accumulation of binucleated cells. Unsynchronized control, mock siRNA-transfected and VASP siRNA-transfected HeLa cells were lysed at $72 \mathrm{~h}$ after transfection, and cell extracts were analyzed by Western blotting using (A) anti-VASP and anti-GAPDH antibodies and (B) anti-p-VASP S157 and anti-GAPDH antibodies. (C) Unsynchronized control and VASP siRNA-transfected cells were fixed at $72 \mathrm{~h}$ after transfection and stained with Hoechst 33342. The percentage of binucleated cells was determined. The mean \pm SD of 5 independent experiments is shown. (D) Control and VASP siRNA-transfected cells were fixed at $72 \mathrm{~h}$ after transfection and visualized with anti- $\alpha$-tubulin antibody (red) and Hoechst 33342 (blue). Binucleated cells were shown. (E) Unsynchronized control and VASP siRNA-transfected cells were subjected to FACS analysis, and the percentage of $\mathrm{x} 4 \mathrm{n}$ cells was determined. The mean $\pm \mathrm{SD}$ of 3 independent experiments is shown. Control cells $(\mathrm{F})$ and VASP siRNA-transfected cells $(\mathrm{G})$ were synchronized with a double thymidine block and released into fresh medium. Whole cell extracts were prepared at the different time points and analyzed by Western blotting using anti-VASP, anti-p-VASP S157, anti-p-H3 S10 and anti-GAPDH antibodies, respectively. The expression of p-H3 S10 and GAPDH proteins in each fraction was detected by Western blotting. The representative band images are shown in the upper panel. Densitometric analysis of the bands is shown in the lower panel.

$\sim 10 \mathrm{~h}$ after release (Fig. 2A1 and A2), and at $11 \mathrm{~h}$ (Fig. 2B1 and B2) with $\mathrm{H} 89$ treatment $(1 \mu \mathrm{M}), 11 \mathrm{~h}$ (Fig. $2 \mathrm{C} 1$ and $\mathrm{C} 2)$ with KT5823 treatment $(2 \mu \mathrm{M}), 14 \mathrm{~h}$ (Fig. 2D1 and D2) with Go6983 treatment $(1 \mu \mathrm{M})$ and $14 \mathrm{~h}$ (Fig. 2E1 and E2) with a combination of the inhibitors, suggesting that p-VASP S157 is required for $\mathrm{G}_{2} / \mathrm{M}$ progression. However, none of their inhibitors nor their combination was capable of completely preventing the phosphorylation of VASP at S157 during progression (Fig. 2).

Depletion of VASP causes a further delay in $G_{2} / M$ progression and a defect in the completion of cytokinesis. Since the kinase inhibitors could not completely prevent the phosphorylation of VASP, we applied RNA interference to see the effect of the silencing of VASP expression on the phosphorylation of VASP and $\mathrm{G}_{2} / \mathrm{M}$ progression. Double-stranded siRNA targeting VASP was transfected into unsynchronized HeLa cells. Western blotting of the whole lysate of the cells verified that the siRNA not only specifically depleted the expression of VASP (Fig. 3A), but also reduced the level of p-VASP S157 (Fig. 3B). Immunofluorescence assay showed that VASP siRNA caused an increase in binucleated cells (Fig. 3D). Approximately $20 \%$ of the cells transfected with VASP siRNA

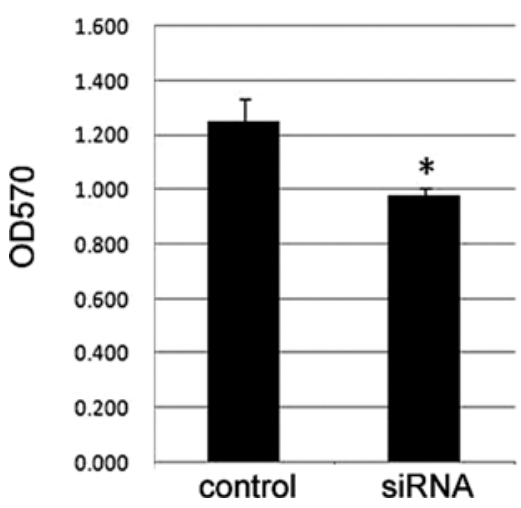

Figure 4. Depletion of p-VASP S157 inhibits the proliferation of HeLa cells. Cell growth was determined with the MTT assay. Compared to the control, cell growth was markedly decreased after transfection with VASP siRNA. The mean \pm SD of 3 independent experiments is shown.

appeared as binucleated cells, compared to less than $2 \%$ of the control cells (Fig. 3C). VASP siRNA also resulted in an increase in the percentage of $\mathrm{x} 4 \mathrm{n}$ cells compared to control cells (Fig. 3E). These data suggested that cell cycle progression was disturbed in VASP-knockdown cells. To identify the 
effect of VASP depletion on $\mathrm{G}_{2} / \mathrm{M}$ progression, control and VASP siRNA-transfected cells were synchronized at the $G_{1} / S$ boundary with a double thymidine block. After being released into fresh medium, the cells were harvested at the indicated time points and the lysate was analyzed by Western blotting. The level of p-H3 S10 was detected to analyze changes in $\mathrm{G}_{2} / \mathrm{M}$ progression. The results showed that there was nearly no increase in the level of p-VASP S157 during $\mathrm{G}_{2} / \mathrm{M}$ progression in VASP siRNA-transfected cells. In mock-transfected cells, maximal accumulation of p-H3 S10 occurred $10 \mathrm{~h}$ after release from the thymidine block (Fig. 3F). By contrast, in VASP-depleted cells, p-H3 S10 reached the maximal level $4 \mathrm{~h}$ later (Fig. 3G).

Depletion of VASP causes inhibition of the proliferation of HeLa cells. HeLa cells were transfected with VASP siRNA for $72 \mathrm{~h}$ and the MTT assay was applied to detect the proliferation of the cells. The results showed that the growth of the cells was markedly inhibited by VASP siRNA. Compared to the control cells (Fig. 4), there was a significant decrease in the proliferation of VASP siRNA transfected cells $(\mathrm{P}<0.05)$.

\section{Discussion}

VASP is highly expressed in focal adhesions along stress fibers and in areas with highly dynamic membrane activity, such as the extending lamellipodia and filopodia (20-23). The activity of Ena/VASP family proteins is regulated by phosphorylation, and phosphorylation at different sites has different functions. For example, previous studies have shown that S157 phosphorylated VASP stimulates cell proliferation, while S239 phosphorylated VASP exerts an inhibitory effect on cell proliferation (24). Our results showed that p-VASP S157 was related to cell cycle progression, and suggest a novel function and action mechanism for this protein.

The $\mathbf{M}$ phase comprises mitosis and cytokinasis, which are the most spectacular points in the cell cycle. Errors in the choreography of these processes lead to aneuploidy or genetic instability, fostering cell death or disease. Sister chromatin separation is one of the important events during this phase. This task is performed by MTs that assemble into a spindleshaped apparatus around the chromosomes. The mitotic spindle is a complex structure based on a bipolar array of MTs and interacting proteins. Timely assembly and disassembly of the spindle are extremely complex processes, involving numerous molecules, such as MT-associated protein, motor protein, MT severing protein and MT destabilizing protein. These proteins are essential for maintaining the integrity of the spindle and cell cycle progression (25-28). Since our previous study showed that p-VASP S157 was localized on spindle, we speculated that it may contribute to cell cycle progression. In the present study, we showed that p-VASP S157, but not VASP or p-VASP S239, were bound with $\alpha$-tubulin and increased during $\mathrm{G}_{2} / \mathrm{M}$ progression, indicating that VASP phosphorylation of S157 is closely related to cell cycle progression. Through the analysis of the accumulation of p-H3 S10, a known marker of $\mathrm{G}_{2} / \mathrm{M}$ progression, the decrease of $\mathrm{p}$-VASP S157 was shown to be correlated with a significant delay in the progression. This suggests that p-VASP S157 may be a potential regulator of the cell cycle.
VASP is the substrate of several protein kinases, including protein kinases A, C and G. In this study, we applied the inhibitors of these kinases to identify the kinase that is relevant to the phosphorylation of VASP during mitosis. However, each of the inhibitors alone only partially prevented phosphorylation. The combination of the inhibitors also failed to completely block phosphorylation. This suggests two possibilities: i) all the above protein kinases may participate in the phosphorylation process of p-VASP S157; therefore, several signaling pathways may converge on the phosphorylation of VASP to regulate the assembly of the spindle and the cell cycle process. ii) Unknown kinase(s) may take VASP as a substrate. Further study is required to determine the candidate(s). There are many other substrates of these protein kinases, and changes in their phosphorylation status may contribute to the delay in $\mathrm{G}_{2} / \mathrm{M}$ progression. Therefore, the results of kinase inhibition do not elucidate the exact role of p-VASP in the cell cycle. However, they do suggest that p-VASP is correlated with progression.

We also applied RNA interference to study the effect of the depletion of VASP on the cell cycle. This technique not only silenced the expression of VASP, but also efficiently


sion in HeLa cells. In conjunction, there was a further delay in the progression of mitosis and an accumulation of binucleated and $x 4 n$ cells. On the one hand, these results further confirm the regulatory role of p-VASP $\mathrm{S} 157$ in $\mathrm{G}_{2} / \mathrm{M}$ progression. On the other, they suggest that this phosphorylated protein also has an effect on cytokinesis. This is in accord with our previous finding, that p-VASP S157 is located at the cleavage furrow between two separating cells (18). Again, siRNA not only decreased phosphorylated VASP, but also depleted its expression. It cannot distinguish the roles of VASP and p-VASP, but suggests the correlation of p-VASP with $\mathrm{G}_{2} / \mathrm{M}$ progression.

In conclusion, we provide evidence that p-VASP S157 is correlated with $\mathrm{G}_{2} / \mathrm{M}$ progression and cytokinesis in $\mathrm{HeLa}$ cells. However, further studies, including experiments with cell-free Xenopus laevis egg extracts and mutations in the phosphorylation site of VASP, are required to provide direct evidence that $\mathrm{p}$-VASP is a potential regulator of spindle assembly. Elucidation of this enigmatic protein will contribute to studies on cell cycle progression.

\section{Acknowledgements}

This study was supported by the Innovation Grant of Jiangsu University and a grant from the National Natural Science Foundation of China (no. 30470891).

\section{References}

1. Nousiainen M, Silljé HH, Sauer G, Nigg EA and Körner R: Phosphoproteome analysis of the human mitotic spindle. Proc Natl Acad Sci USA 103: 5391-5396, 2006.

2. Kimura M, Kotani S, Hattori T, Sumi N, Yoshioka T, Todokoro K and Okano Y: Cell cycle-dependent expression and spindle pole localization of a novel human protein kinase, Aik, related to Aurora of Drosophila and yeast Ipl1. J Biol Chem 272: 13766-13771, 1997.

3. Waters JC and Salmon E: Pathways of spindle assembly. Curr Opin Cell Biol 9: 37-43, 1997. 
4. Heald R and Walczak CE: Microtubule-based motor function in mitosis. Curr Opin Struct Biol 9: 268-274, 1999.

5. Gaglio T, Saredi A and Compton DA: NuMA is required for the organization of microtubules into aster-like mitotic arrays. J Cell Biol 131: 693-708, 1995.

6. Wilde A, Lizarraga SB, Zhang L, Wiese C, Gliksman NR, Walczak CE and Zheng Y: Ran stimulates spindle assembly by altering microtubule dynamics and the balance of motor activities. Nat Cell Biol 3: 221-227, 2001.

7. Kapitein LC, Peterman EJ, Kwok BH, Kim JH, Kapoor TM and Schmidt CF: The bipolar mitotic kinesin Eg5 moves on both microtubules that it crosslinks. Nature 435: 114-118, 2005.

8. Shen E, Lei Y, Liu Q, Zheng Y, Song C, Marc J, Wang Y, Sun L and Liang Q: Identification and characterization of INMAP, a novel interphase nucleus and mitotic apparatus protein that is involved in spindle formation and cell cycle progression. Exp Cell Res 315: 1100-1116, 2009.

9. Yang S, Liu X, Yin Y, Fukuda MN and Zhou J: Tastin is required for bipolar spindle assembly and centrosome integrity during mitosis. FASEB J 22: 1960-1972, 2008

10. Barzik M, Kotova TI, Hiqqs HN, Hazelwood L, Hanein D, Gertler FB and Schafer DA: Ena/VASP proteins enhance actin polymerization in the presence of barbed end capping proteins. $\mathbf{J}$ Biol Chem 280: 28653-28662, 2005

11. Bear JE, Svitkina TM, Krause M, Schafer DA, Loureiro JJ, Strasser GA, Maly IV, Chaga OY, Cooper JA, Borisy GG and Gertler FB: Antagonism between Ena/VASP proteins and actin filament capping regulates fibroblast motility. Cell 109: 509-521, 2002.

12. Markert T, Krenn V, Leebmann J and Walter U: High expression of the focal adhesion- and microfilament-associated protein VASP in vascular smooth muscle and endothelial cells of the intact human vessel wall. Basic Res Cardiol 91: 337-343, 1996.

13. Draijer R, Vaandrager AB, Nolte C, de Jonge HR, Walter U and van Hinsbergh VW: Expression of cGMP-dependent protein kinase I and phosphorylation of its substrate, vasodilator-stimulated phosphoprotein, in human endothelial cells of different origin. Circ Res 77: 897-905, 1995.

14. Wentworth JK, Pula G and Poole AW: Vasodilator-stimulated phosphoprotein (VASP) is phosphorylated on Ser157 by protein kinase C-dependent and -independent mechanisms in thrombinstimulated human platelets. Biochem J 393: 555-564, 2006.

15. Butt E, Abel K, Krieger M, Palm D, Hoppe V, Hoppe J and Walter U: cAMP- and cGMP-dependent protein kinase phosphorylation sites of the focal adhesion vasodilator-stimulated phosphoprotein (VASP) in vitro and in intact human platelets. J Biol Chem 269: 14509-14517, 1994.

16. Gertler FB, Niebuhr K, Reinhard M, Wehland J and Soriano P. Mena, a relative of VASP and Drosophila Enabled, is implicated in the control of microfilament dynamics. Cell 87: 227-239, 1996.
17. Lambrechts A, Kwiatkowski AV, Lanier LM, Bear JE, Vandekerckhove J, Ampe C and Gertler FB: cAMP-dependent protein kinase phosphorylation of EVL, a Mena/VASP relative, regulates its interaction with actin and SH3 domains. J Bio Chem 275: 36143-36151, 2000.

18. Tao Y, Chen YC, Wang Y, Zhang ZJ and Xu WR: Phosphorylated vasodilator-stimulated phosphoprotein is localized on mitotic spindles of the gastric cancer cell line SGC-7901. World J Gastroenterol 12: 7478-7481, 2006

19. Tong Q, Zeng F, Zheng L, Zhao J and Lu G: Apoptosis inducing effects of arsenic trioxide on human bladder cancer cell line BIU-87. Chin Med J 114: 402-406, 2001.

20. Haffner C, Jarchau T, Reinhard M, Hoppe J, Lohmann SM and Walter U: Molecular cloning, structural analysis and functional expression of the proline-rich focal adhesion and microfilamentassociated protein VASP. EMBO J 14: 19-27, 1995.

21. Reinhard M, Halbrügge M, Scheer U, Wiegand C, Jockusch BM and Walter U: The $46 / 50 \mathrm{kDa}$ phosphoprotein VASP purified from human platelets is a novel protein associated with actin filaments and focal contacts. EMBO J 11: 2063-2070, 1992.

22. Rottner K, Behrendt B, Small JV and Wehland J: VASP dynamics during lamellipodia protrusion. Nat Cell Biol 1: 321-322, 1999.

23. Svitkina TM, Bulanova EA, Chaga OY, Vignjevic DM, Kojima S, Vasiliev JM and Borisy GG: Mechanism of filopodia initiation by reorganization of a dendritic network. J Cell Biol 3: 409-421, 2003.

24. Chen L, Daum G, Chitaley K, Coats SA, Bowen-Pope DF, Eigenthaler M, Thumati NR, Walter $U$ and Clowes AW: Vasodilator-stimulated phosphoprotein regulates proliferation and growth inhibition by nitric oxide in vascular smooth muscle cells. Arterioscler Thromb Vasc Biol 24: 1403-1408, 2004.

25. Raemaekers T, Ribbeck K, Beaudouin J, Annaert W, Camp MV, Stockmans I, Smets N, Bouillon R, Ellenberg J and Carmeliet G: NuSAP, a novel microtubule-associated protein involved in mitotic spindle organization. J Cell Biol 162: 1017-1029, 2003.

26. Ribbeck K, Groen AC, Santarella R, Bohnsack MT, Raemaekers T, Köcher T, Gentzel M, Görlich D, Wilm M, Carmeliet G, Mitchison TJ, Ellenberg J, Hoenger A and Mattaj IW: NuSAP, a mitotic RanGTP target that stabilizes and cross-links microtubules. Mol Biol Cell 17: 2646-2660, 2006.

27. Tang TK, Tang CC, Chao YJ and Wu CW: Nuclear mitotic apparatus protein (NuMA): spindle association, nuclear targeting and differential subcellular localization of various NuMA isoforms. J Cell Sci 107: 1389-1402, 1994.

28. Quintyne NJ, Reing JE, Hoffelder DR, Gollin SM and Saunders WS: Spindle multipolarity is prevented by centrosomal clustering. Science 307: 127-129, 2005. 